\title{
EFFECT OF SOLID CONCENTRATION ON A CENTRIFUGAL PUMP PERFORMANCE
}

\author{
S.M. Selim ${ }^{(1)}$, M.A. El-kadi ${ }^{(2)}$, M.A. Younes ${ }^{(3)}$, \\ M.A. Hosien ${ }^{(4)}$, and I.R. Teaima ${ }^{(5)}$ \\ ${ }^{1,2,4)}$ Department of Mechanical Engineering, Faculty of Engineering \\ Minoufiya University, Shebin El-Kom, Egypt \\ ${ }^{3,5)}$ Mechanical and Electrical Research Institute, Delta Barrage, Egypt
}

\begin{abstract}
Study on slurry pump performance has attracted much interest in many engineering fields. The influence of solids concentration on a pump operation has been investigated over the decades. When pumps are required to handle slurries, the pump head and efficiency are mainly affected by the solid size, solid concentration and solid density. The experiments were conducted with water, sand slurry, and clay slurry at operating pump speed. Measurements of power consumption, flow rate, total head developed by the pump and the density of the slurry were made in order to obtain the characteristic curves of the pump. The results have shown that the values of head generated by the pump and its efficiency are not only dependent on solid concentration but are also affected by particle size distribution of the solids and properties of the slurry.

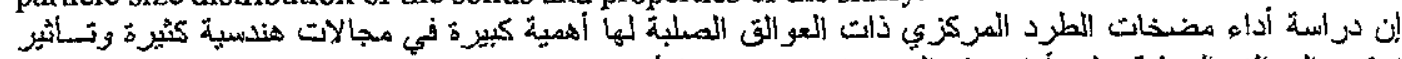

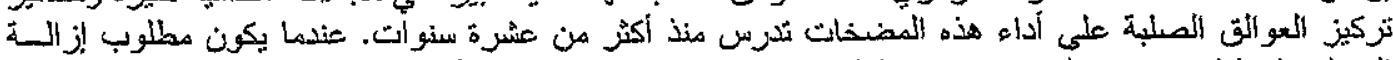

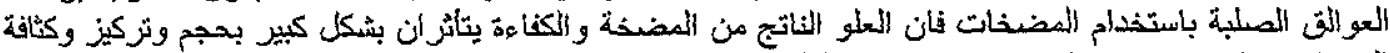

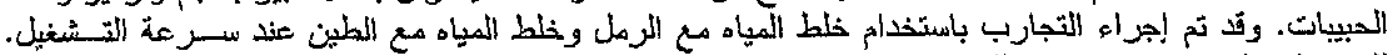

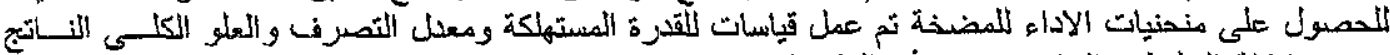

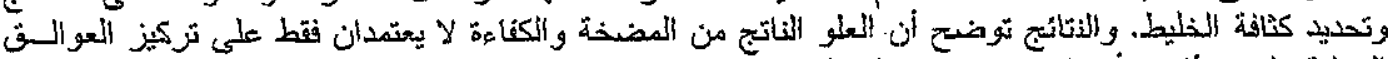

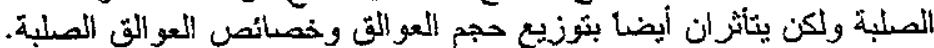

Keyword: Slurry pump-Solids concentration-Head and efficiency ratios-Particle size distribution

\section{NTTRODUCTION}

Centrifugal slurry pumps are being used extensively in pipeline transportation systems because of their capabilities to economically convey large size abrasive solids in bulk. These pumps have been developed by suitably modifying the design of conventional centrifugal pumps to ensure proper flow of solid liquid mixtures and to minimize erosive wear. The head and the efficiency of these pumps with slurries are in general lower in comparison with those pumping pure water due to the presence of suspended solids. Mez [1] carried out experiments to investigate the effects of solid properties such as density, particle size and particle size distribution, and solid concentration up to $40 \%$ by weight on the behavior of centrifugai pumps. The maximum particle size was $125 \mathrm{~mm}$. He observed that the effect of solid concentration on head reduction is linear when pumping coarse grain solids. His results were in agreement with the results obtained by Kazim et al. [2]. Sellgren and Vappling [3] has reported that the decrease in the head is a function of solid concentration, specific gravity and the particle drag coefficient. Wilson [4] presented practical methods for predicting the performance of centrifugal slurry pumps with extremely fine and coarse particles size, density and concentration of solids The results showed that when pumping slurries, the relative reductions in pump head and efficiency were independent of flow rate and pump speed. Sellgren and Vappling [5] observed higher reduction in the efficiency compared to the head developed by rubber-lined pump for solid concentration higher than 20 percent by volume. Sellgren and Addie [6] investigated the effect of solids on the large centrifugal pumps head and efficiency. They used two types of sands and a gravel material with average particle sizes of $0.25,1.5$, and $6 \mathrm{~mm}$, and showed that, for a $70 \%$ of the best efficiency point (BEP) flow rate, the clear water head was dropped by 3.5 , 7 , and $10 \%$ respectively, with a solids concentration of $32 \%$ by weight in centrifugal slurry pumps having impeller diameters of 1.1 and $1.2 \mathrm{~m}$. Gahlot et al. [7] studied the effect of density, size distribution, and concentration of solids on the characteristics of centrifugal pumps. They observed higher drop in the head compared to that in the efficiency. Sellgren and Addie [8] studied the effects of solids on large slurry pumps with impellers 0.8 and $1.2 \mathrm{~m}$ in diameter operating at very high slurry concentrations. They 
observed that the effect of the presence of solids was smaller in larger size pumps compared to small pumps. They also concluded that the reduction in efficiency was normally less than the head reduction in large pumps, while it was equal for smaller units. Kazim et al. [9] performed experiments to study the individual effects of particle size, particle size distribution, specific gravity, and concentration of solids on the performance characteristics of centrifugal pumps. They found that the relative reductions in pump head and efficiency, for a constant concentration of solids, were to be fairly constant over the range of discharge investigated. They also concluded that the relative reduction in efficiency was generally lower than the relative reduction in head at any given flow rate and concentration of solids. Ni et al. [10] focused on pumping of highly concentrated slurries and concluded that the high solids concentration has shown strong impact on the performance characteristics of the pump. For the medium sand slurry, they observed that there exists a critical volumetric concentration in pump head and efficiency drop faster. Sellgren et al. [11] studied the effect of sand-clay slurries on the performance characteristics of centrifugal slurry pumps. They observed that the addition of clay to sand led to a reduction in pipe line friction losses, thus lowering the pumping head and power consumption. Gandhi, et al. [12] developed a methodology based on a loss analysis procedure to predict the performance of centrifugal pumps handling slurries. Their methodology accounts for the constructional differences of the slurry pump when compared with the pure liquid pump. Gandhi, et al. [13] investigated the performance of two centrifugal slurry pumps for three different solid materials, (fly ash, zinc tailing, and bed ash) with different particle size distribution in terms of pump performance parameters. Their results have shown that the values of head and efficiency ratios are not only dependent on solid concentration but are also affected by particle size distribution of the solids and properties of the slurry. They showed that the reduction in head was $2-10 \%$ higher than the reduction in efficiency. They also observed that for concentration less than $30 \%$ by weight, the increase in the input power of the pump could be related to the specific gravity of slurry. In addition the relative reductions in pump head and efficiency can be considered to be the same for the given range of concentration of solids. Gandhi et al. [14] studied the effect of speed on the performance characteristics of a centrifugal slurry pump. They concluded that the affinity relations applicable to conventional pumps for head and capacity can be applied to the slurry pumps handling water and slurries at low solid concentration $(<20 \%$ by weight). For higher solid concentrations, these relationships need to be corrected by taking into account the effect of solids. Engin and Gur [15] have developed a correlation to predict head reductions of centrifugal pumps handling slurries. Their correlation takes into account the individual effects of particle size, particle size distribution, specific gravity and concentration of solids and impeller exit diameter on the pump performance. Based on the previous studies it is shown that there is a conflict information about the reduction in head and efficiency. An attempt has been made to establish the effect of multi sized concentrated slurries on the performance of the centrifugal pump.

\section{EXPERIMENTAL WORK}

\subsection{Experimental Apparatus and Instrumentation}

In the present study experiments were conducted to determine the individual effects of particle size, particle size distribution and concentration of solids on the centrifugal punp performance characteristics.

The experimental data were obtained by conducting experiments using a specially designed and fabricated experimental facility. The schematic view of the test rig is shown in Fig.1.

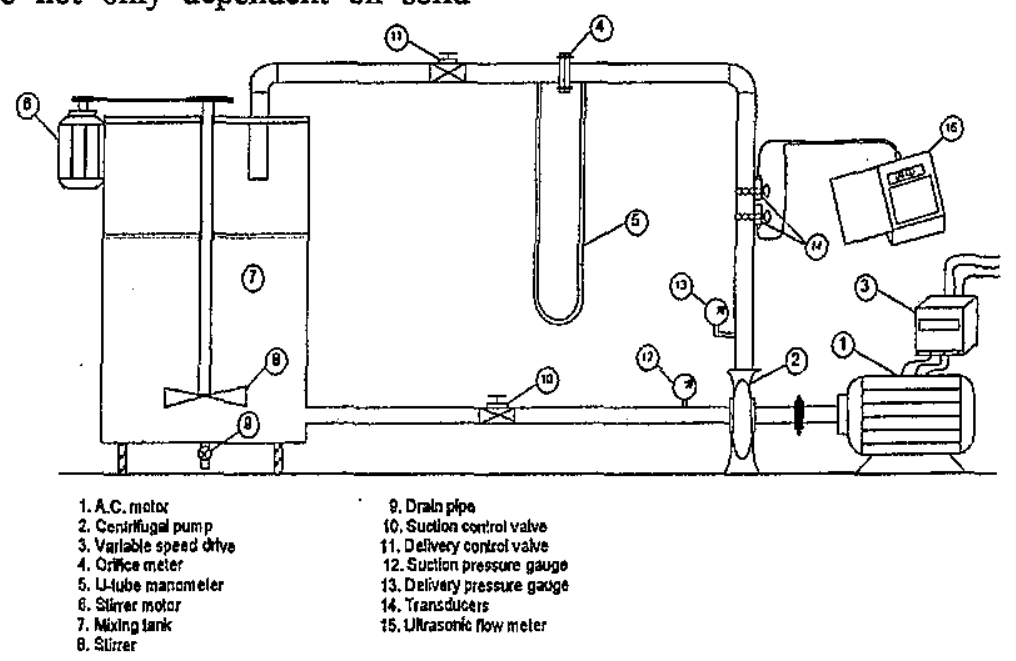

Fig.1 Experimental test rig and instrumentation. 
The mixture was prepared using a stirrer (8) in a mixing tank (7) by adding the required quantities of solids into the water. The pump discharge was controlled by using delivery valve (11). The slurry was drawn from the mixing tank by the pump and circulated through a closed test loop. The suction and delivery heads were measured by using a Bourdon pressure gauge. The calibration of these gauges was periodically checked using a weight type reference gauge. The flow rate was measured by using orifice meter (4) and Ultrasonic flow meter (15). Both flow meters are calibrated with water and slurry by measuring the collected volume of water or slurry in measuring tank over a known time interval. The pump (2) is directly coupled to a $7.5 \mathrm{HP}-\mathrm{AC}$ motor (1). Atypical centrifugal pump having specifications $\mathrm{d}_{1}=54 \mathrm{~mm}, \mathrm{~d}_{2}=175 \mathrm{~mm}, \mathrm{~b}_{1}=10.5 \mathrm{~mm}, \mathrm{~b}_{2}=5 \mathrm{~mm}$, $\beta_{1}=21.5^{\circ}, \beta_{2}=28^{\circ}$ and $z=6$. (backward curved) was used in the experiments. The pump speed measured by using variable speed inverter (3). The input power, $P(k W)$ to the electric motor was measured by using a calibrated wattmeter with an accuracy of $0.36 \%$. The meters were checked before and after each set of runs.

\subsection{Test Method}

In order to study the effect of the suspended solids on the centrifugal pump characteristics, testes were conduced with three sorts of narrowly graded sands with specific gravity 2.52 and one sort of clay slurries, (fine sand, medium sand, coarse sand and clay). The physical properties of the materials are shown in tablel. The particle size distributions of the materials were sieve analysis. The weighted mean diameter $\left(d_{w}\right)$ of different materials was calculated and the mass median diameter $\left(d_{s_{0}}\right)$ was obtained from the cumulative percentage undersized-particle diameter Fig. 2.

Table1. Physical properties of the material used.

\begin{tabular}{|c|c|c|c|}
\hline Materials & $\begin{array}{c}\text { Specific } \\
\text { gravity } \\
\mathrm{S}(-)\end{array}$ & $\begin{array}{c}\text { Mass median } \\
\text { diameter(mm) } \\
\mathrm{d}_{50}\end{array}$ & $\begin{array}{c}\text { Weighted } \\
\text { mean } \\
\text { diameter } \\
(\mathrm{mm}) \\
\mathrm{d}_{\mathrm{w}}\end{array}$ \\
\hline $\begin{array}{c}\text { Fine to } \\
\text { medium } \\
\text { sand }\end{array}$ & 2.52 & 0.152 & 0.152 \\
\hline $\begin{array}{c}\text { Medium } \\
\text { sand }\end{array}$ & 2.52 & 0.203 & 0.206 \\
\hline $\begin{array}{c}\text { Coarse to } \\
\text { medium } \\
\text { sand }\end{array}$ & 2.52 & 0.341 & 0.348 \\
\hline Clay & 2.08 & 0.003 & 0.0035 \\
\hline
\end{tabular}

Measurements were made with six different concentrations of each solid material for the operating speed of the pump. Following the completion of the pump test with water, a recalculated amount of solid material was slowly added to water in the mixing tank with the stirrer in operation. The mixture was kept in circulation for approximately 15 minutes to assure a complete mixing before starting any measurements. The delivery valve was opened while the pump in operation at a constant rotating speeds. The power input to the motor, the flow rate, and the suction and delivery pressure were recorded. The density of the mixture $\left(\rho_{\mathrm{m}}\right)$ was determined from the value of solid concentration. The measurements were repeated for various settings of the delivery valve, various concentrations of solid particles and various types of materials.

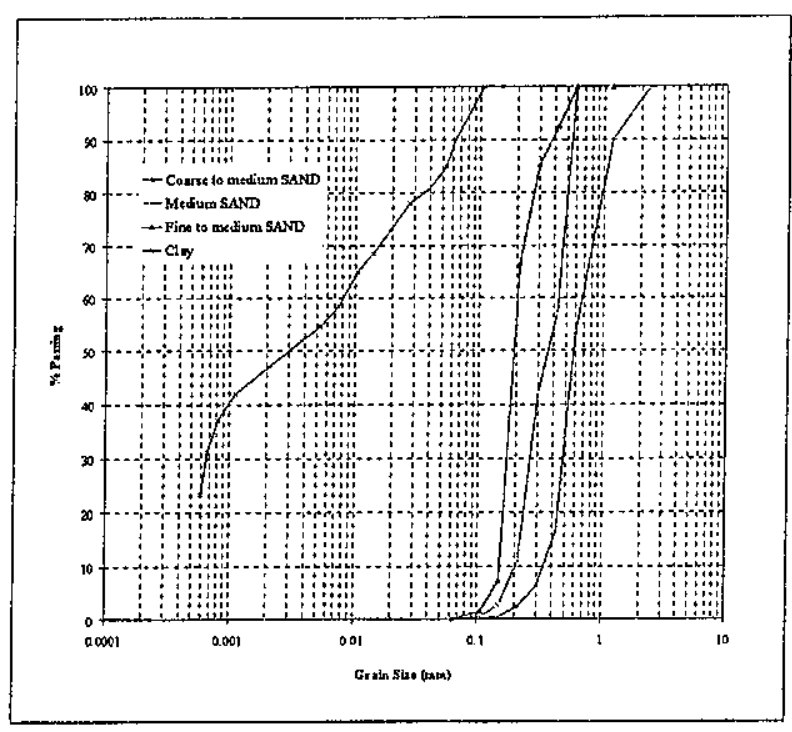

Fig.2 Particle size distribution of the material used

\section{EXPERUMENTAL RESULTS}

\subsection{Effect of concentration of solids}

The experimental results on the centrifugal pump with water and different solid-liquid mixtures and clay concentration ratios at operating speed of 3000 rpm are presented in Figs. (3-6). These figures show the performance characteristics of centrifugal pump at a speed of $3000 \mathrm{rpm}$ for water and different concentration ratios (by weight) of fine sand, medium sand, coarse sand and clay slurries. The concentrations of particles range (5\%-32\%) for sand slurries and (5\%-36\%) for clay slurry. From the results it is shown that with increasing the percentage of concentration, the pump head and efficiency decreased and pump input power increasing in comparison with the performance of the pump with clear water. From the results it is shown that all curves have the same trend as that with clear water. 
S.M. Selim, M.A. El-kadi, M.A. Younes, M.A. Hosien, and I.R. Teaima, "Effect of Solid Concentration on ... "

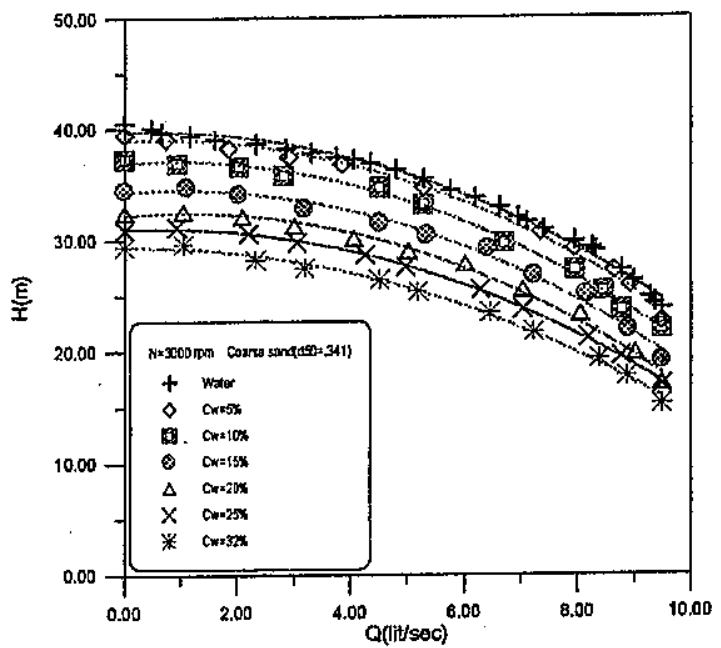

(a) Head-Capacity Characteristics

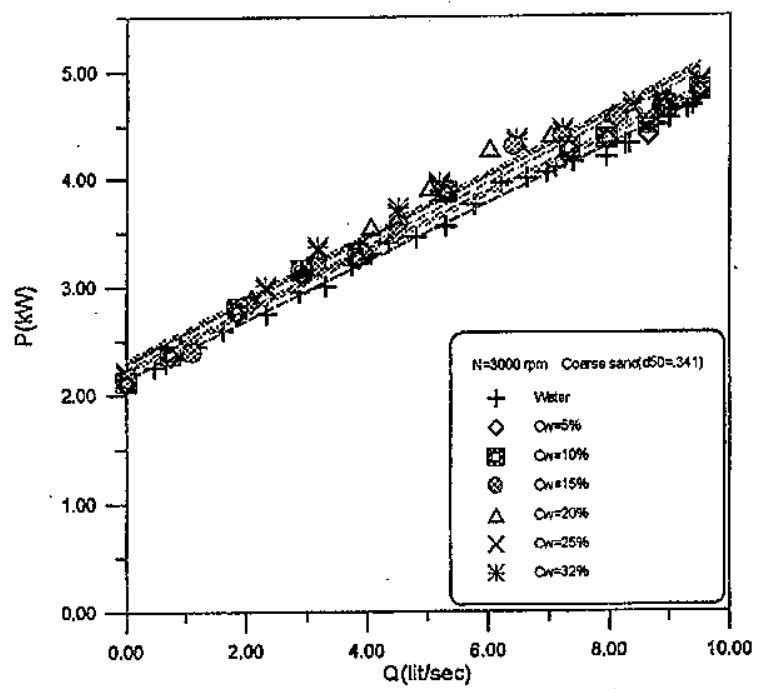

(b) Power-Capacity Characteristics

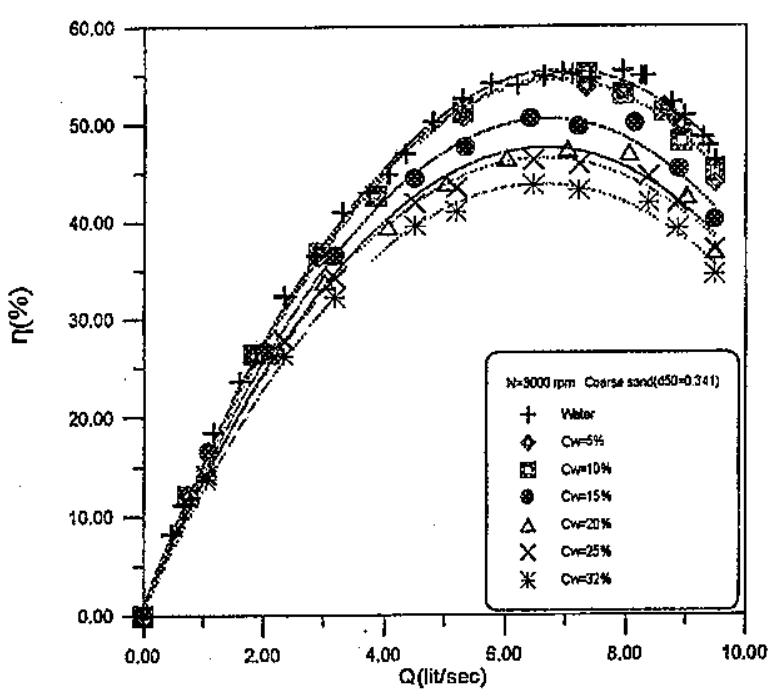

(c) Efficiency-Capacity Characteristics

Fig.3 Performance characteristics with coarse

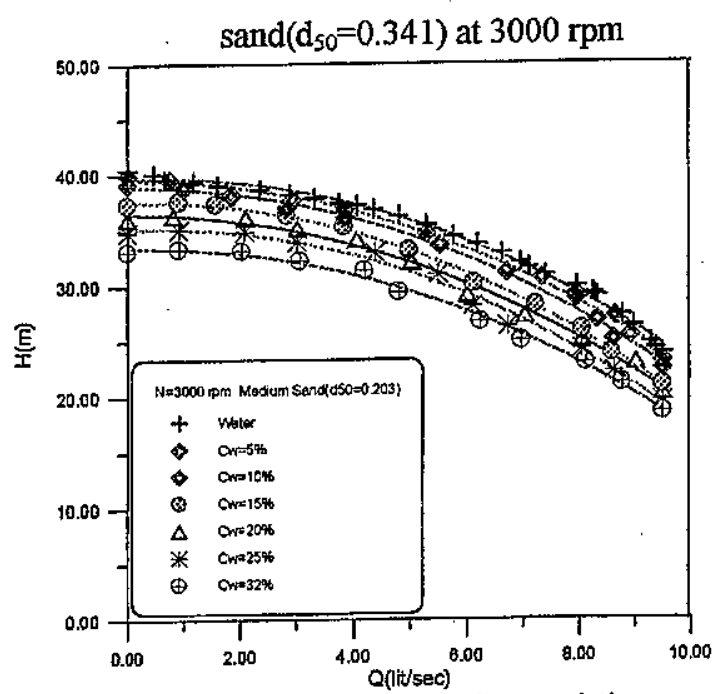

(a) Head-Capacity Characteristics

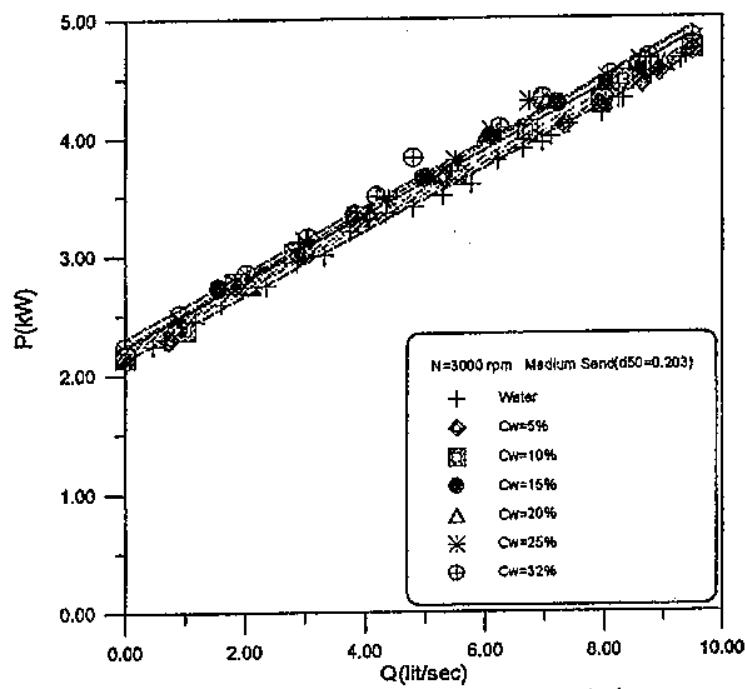

(b) Power-Capacity Characteristics

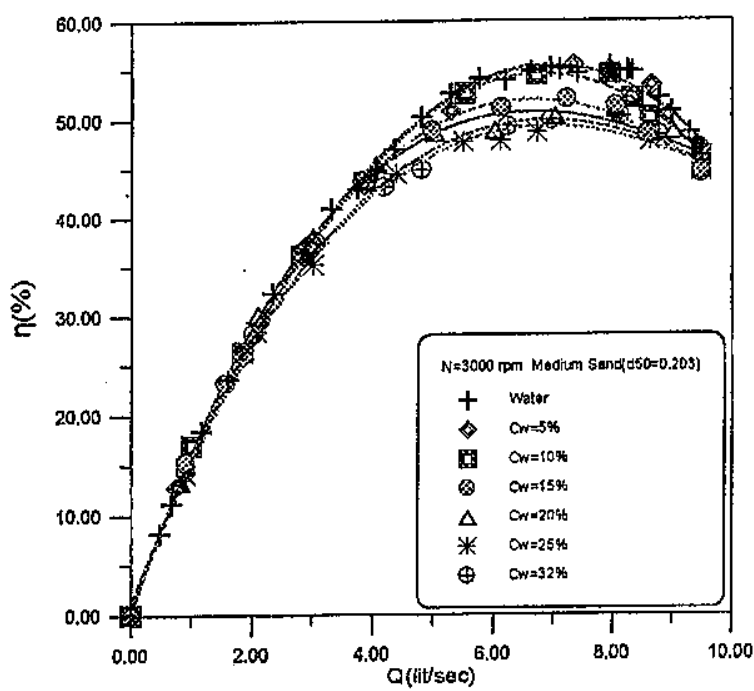

(c) Efficiency-Capacity Characteristics

Fig.4 Performance characteristics with medium 
S.M. Selim, M.A. El-kadi, M.A. Younes, M.A. Hosien, and I.R. Teaima, "Effect of Solid Concentration on ... "

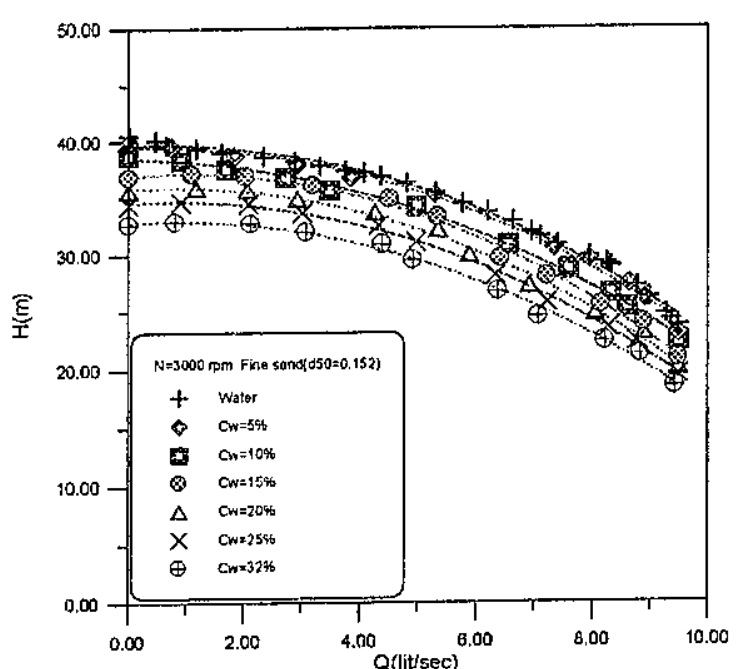

(a) Head-Capacity Characteristics

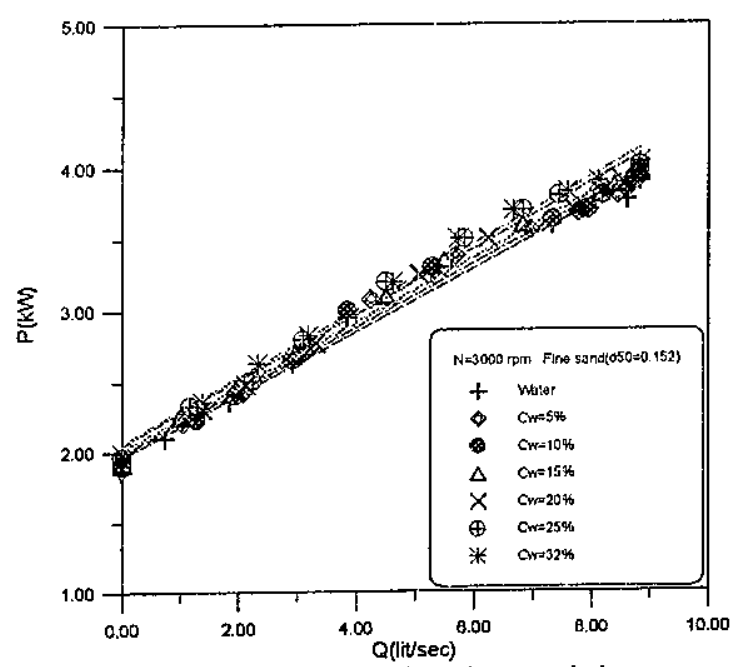

(b) Power-Capacity Characteristics

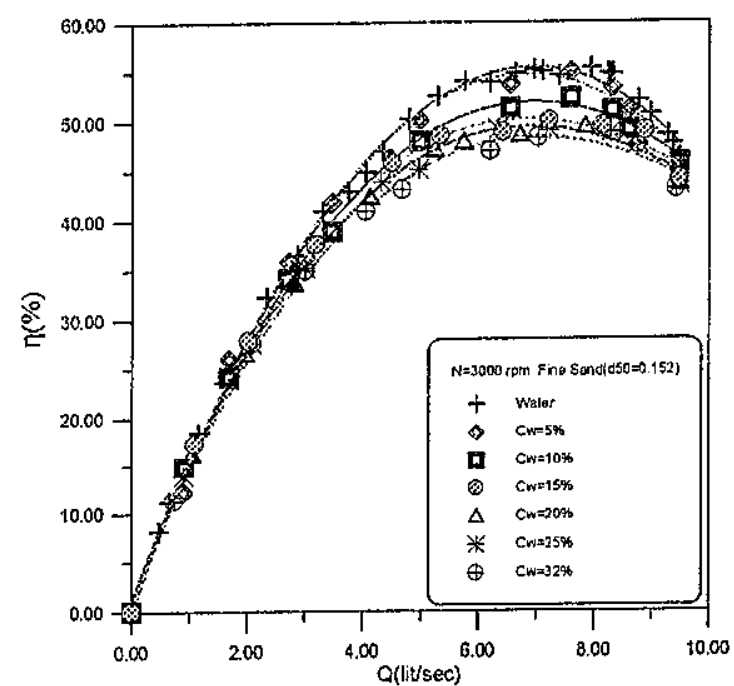

(c) Efficiency-Capacity Characteristics

Fig.5 Performance characteristics with fine sand $\left(\mathrm{d}_{50}=0.152\right)$ at $3000 \mathrm{rpm}$

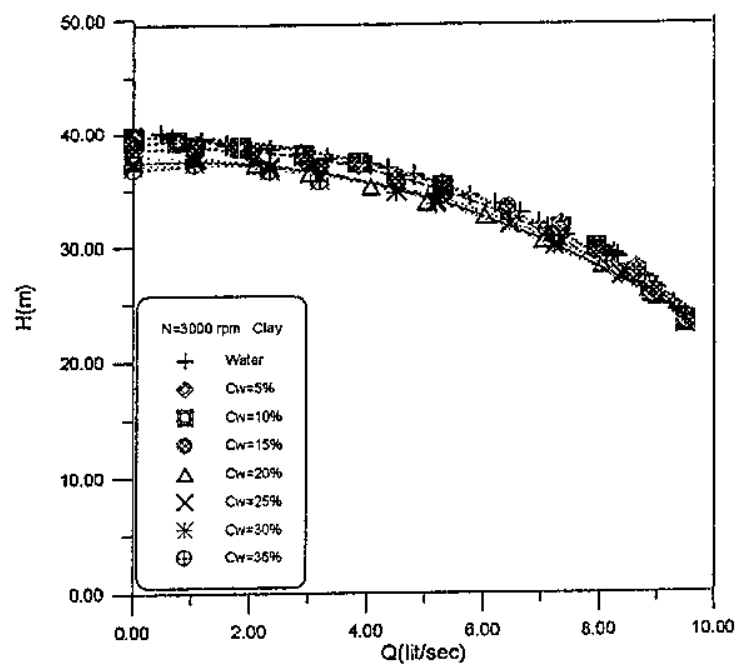

(a) Head-Capacity Characteristics

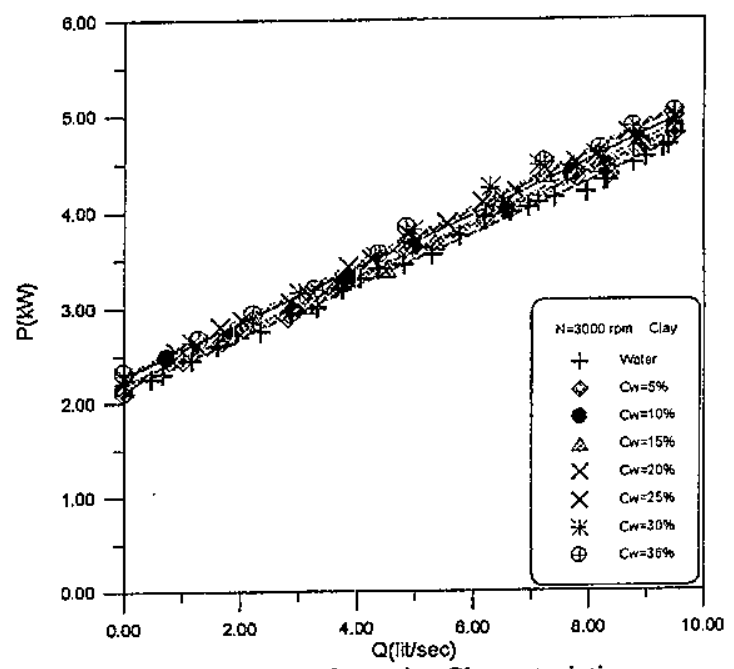

(b) Power-Capacity Characteristics

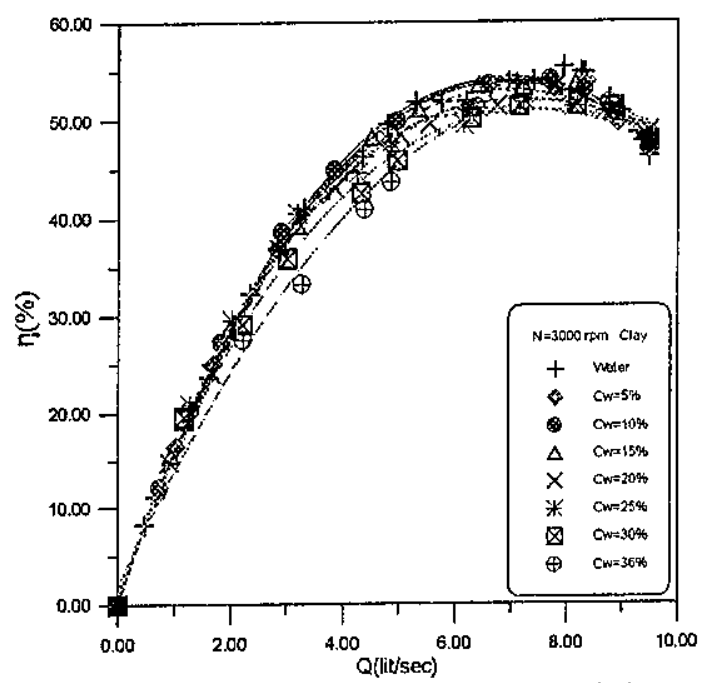

(c) Efficiency-Capacity Characteristics

Fig.6 Performance characteristics with clay at 3000 rpm 


\subsection{Effect of particle size distribution of the solids}

The particle size distribution of the solids has a strong influence on the pump performance characteristics. The effect of particles size distribution on the centrifugal pump performance at the pump speed $3000 \mathrm{rpm}$ and constant concentration by weight $(\mathrm{Cw}=5 \%)$ is represented in Figs. (7-8). The Figures it can be seen that increasing the particle size has a little effect on the pump head and efficiency and also on the consumed pump power reduction. Figs. (9-10) present results for concentration ratio $(\mathrm{Cw}=32 \%)$ and show that increasing the concentration ratio has a pronounced reduction on the pump head and efficiency and also the consumed power required for the pump is increased.

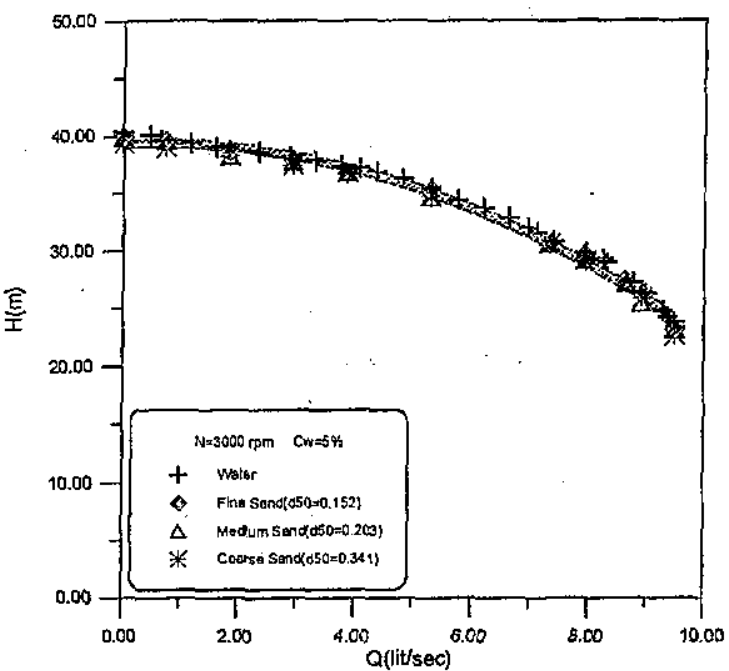

(a) Head-Capacity Characteristics

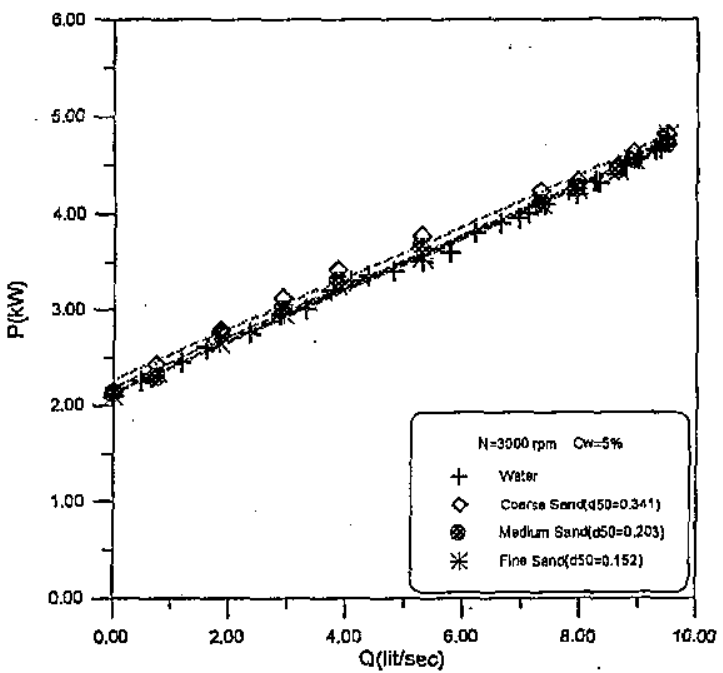

(b) Power-Capacity Characteristics

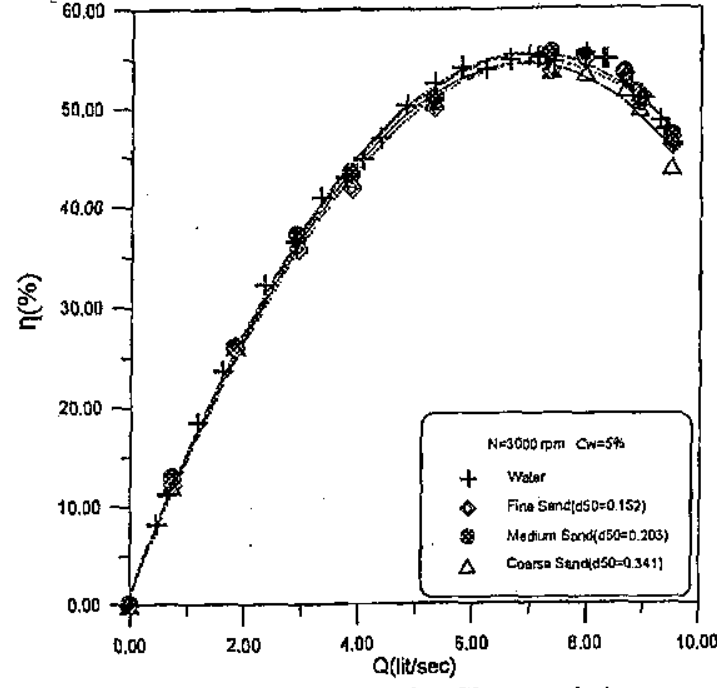

(c) Efficiency-Capacity Characteristics

Fig.7 Performance characteristics with different particle size at $C w=5 \%$ and $3000 \mathrm{rpm}$

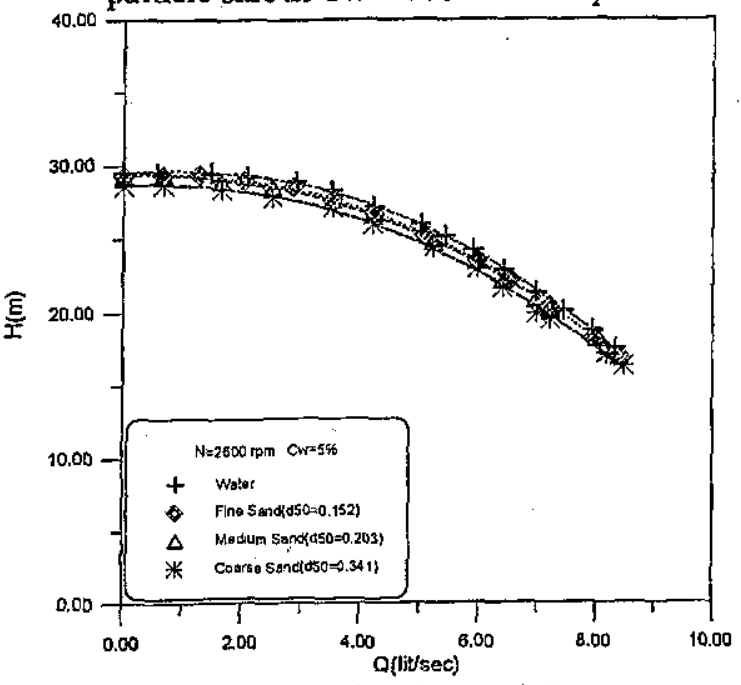

(a) Head-Capacity Characteristics

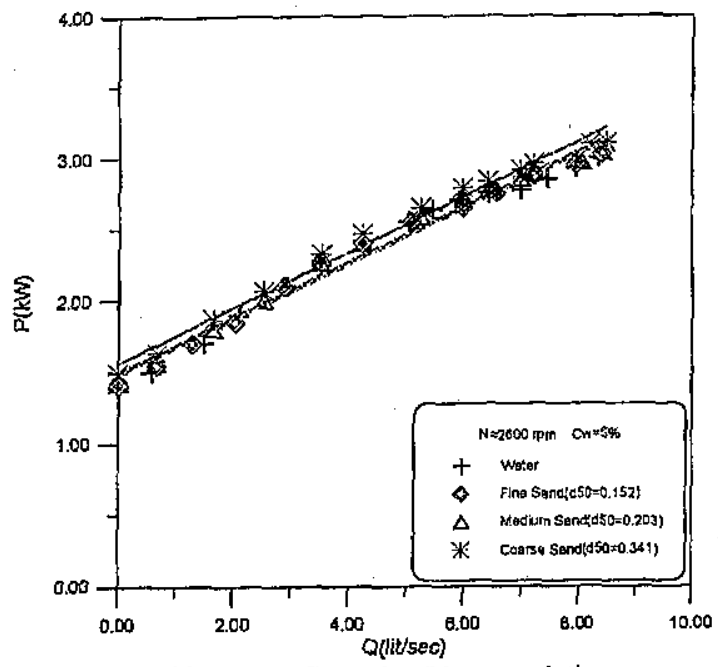

(b) Power-Capacity Characteristics 
S.M. Selim, M.A. El-kadi, M.A. Younes, M.A. Hosien, and I.R. Teaima, "Effect of Solid Concentration on ... "

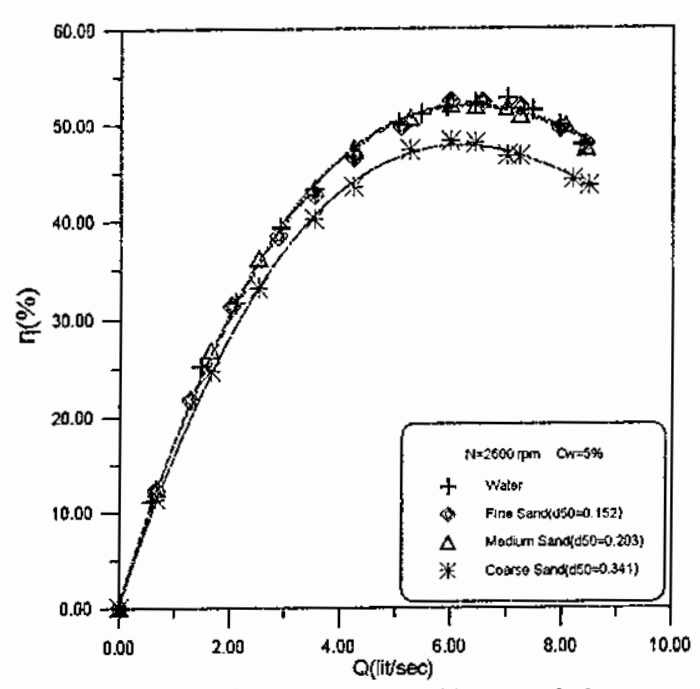

(c) Efficiency-Capacity Characteristics

Fig.8 Performance characteristics with different

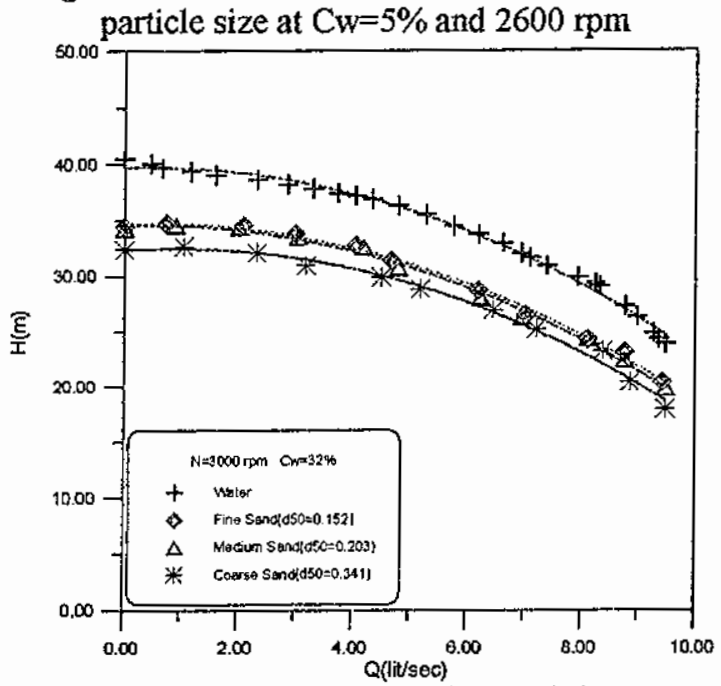

(a) Head-Capacity Characteristics

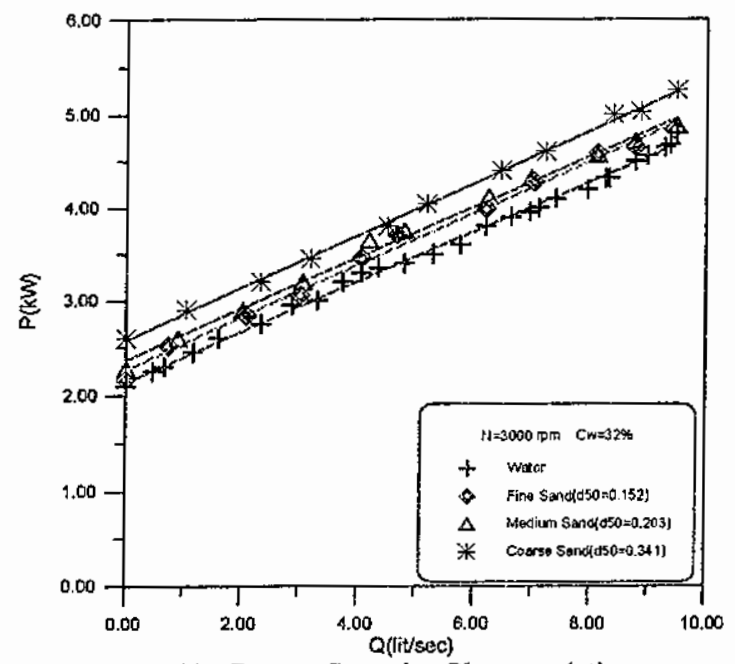

(b) Power-Capacity Characteristics

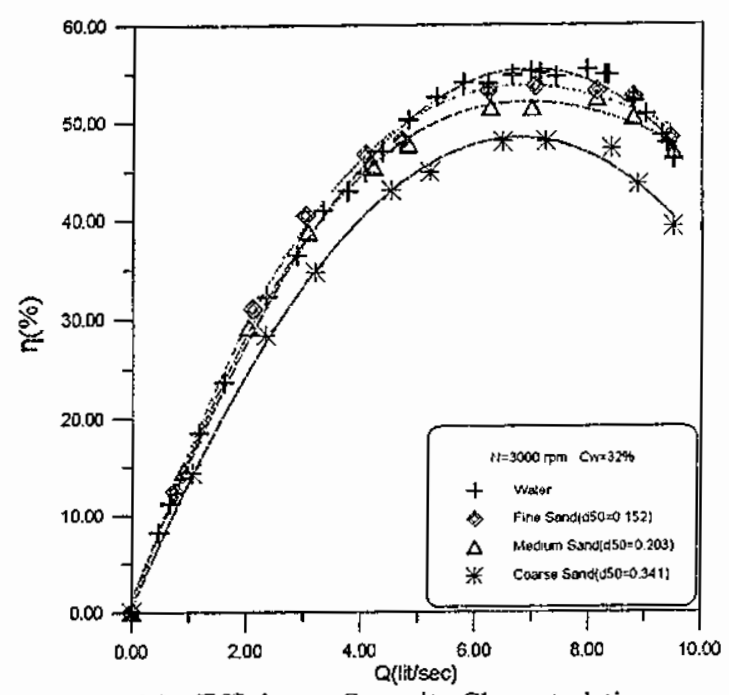

(c) Efficiency-Capacity Characteristics

Fig.9 Performance characteristics with different particle size at $\mathrm{Cw}=32 \%$ and $3000 \mathrm{rpm}$

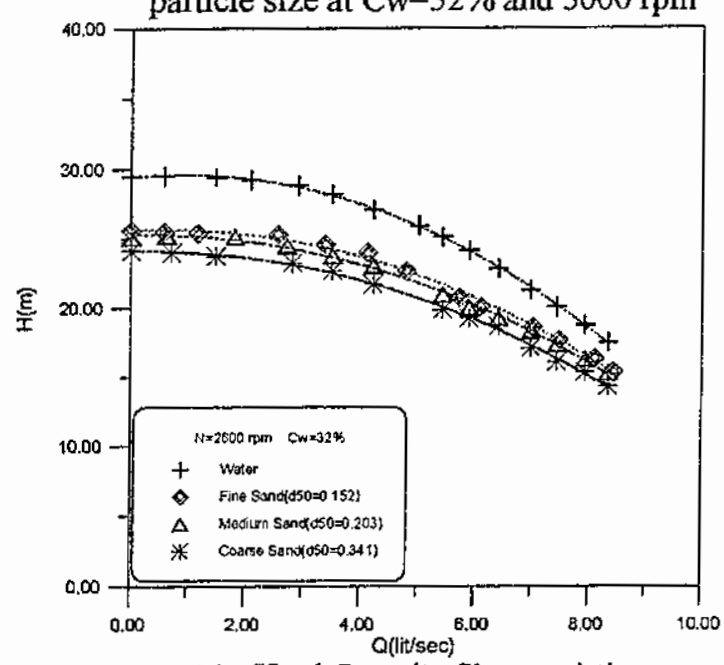

(a) Head-Capacity Characteristics

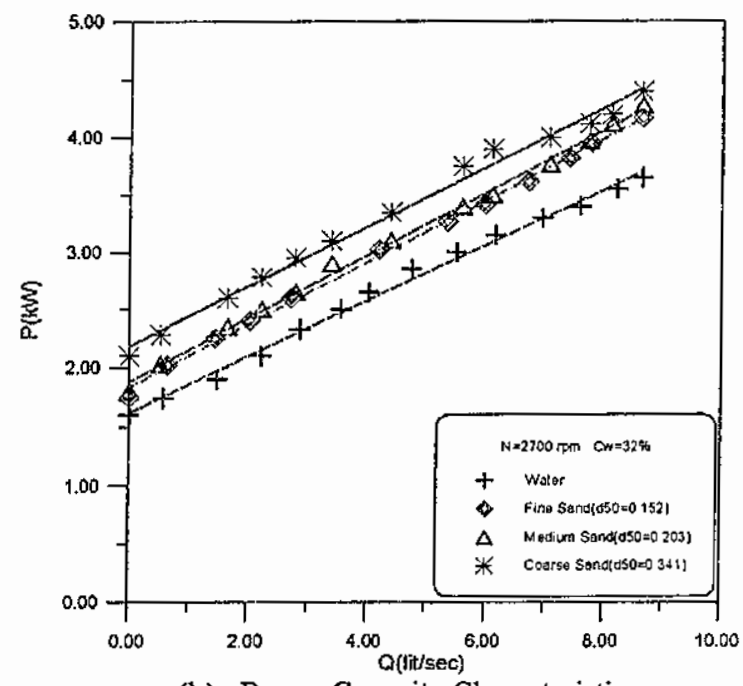

(b) Power-Capacity Characteristics 


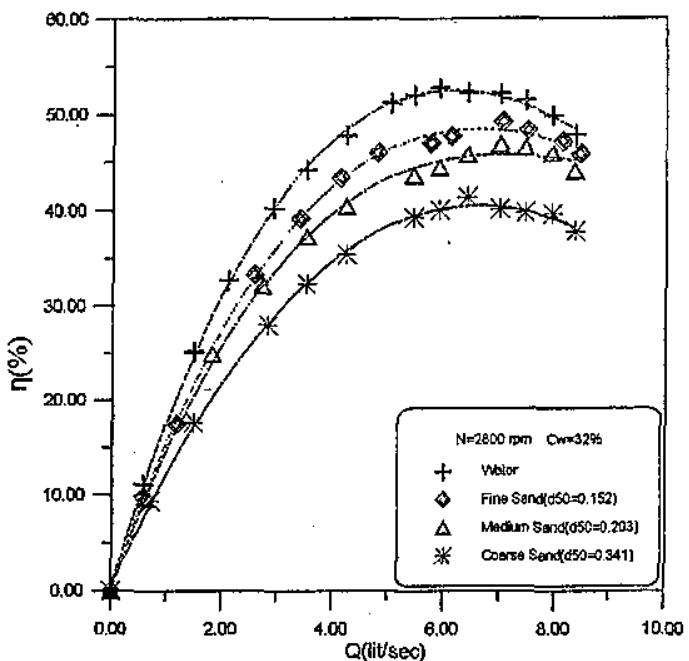

(c) Efficiency-Capacity Characteristics

Fig.10 Performance characteristics with different particle size at $\mathrm{CW}=32 \%$ and $2600 \mathrm{rpm}$

\section{DISCUSSION}

To bring out the relative pump performance with four solid materials over the entire range, the measured data is expressed in terms of head ratio (HR), power ratio (PR), and efficiency ratio (ER). Figs. (11-13) represent linear relations between the head ratio (HR), power ratio (PR), and efficiency ratio (ER), with solid concentration at pump best efficiency point (BEP).

From Figure (11) it is shown that with the increasing of solid concentration and particle size the head ratio $\mathrm{HR}$ decreasing. This agree with the results of $\mathrm{Ni}$ et al. [10], Sellgren and Addie [6], and Gandhi et al. [13]. From this Figure it is also shown that clay slurry has higher head ratio compared to sand slurries. Figure (12) show the variation of power ratio PR with solid concentration at the best efficiency point. From this Figure it is shown that, the power ratio increases linearly with increasing the solid concentration for all types of slurries. For coarse sand slurry the power ratio is higher than those for the medium and fine sand. While for clay the power ratio is lower than sand. For the clay, fine and medium sand slurries, $E R \approx H R$, and therefore $P R \approx I$ holds for the concentration at least up to $10 \%$. From this Figure it is also shown that, the rate of increasing of PR for all types of slurries is lower than the rate of increasing of the mixture specific gravity. This is in line with the results of Gandhi et al. [13]. Figure (13) show the variation of efficiency ratio ER with solid concentration at the best efficiency point. From this Figure it is shown that with increasing the solid concentration and particle size the efficiency ratio decreases. The above experimental results show that, the head, power and efficiency of the pump are affected by the presence of suspended solid particles in the carrier liquid. Comparison of the results show that, the values of ER are always higher than the corresponding HR values for all solid materials depending upon the concentration and properties of the solid material. This is in agreement with the results of Gandhi et al. [13], and Gahlot et al. [7]. Figs. (14-16) show the comparison between measured experimental results of head ratio, and efficiency ratio with the published results obtained by Kazim et al. [2] and $\mathrm{Ni}$ et al. [10] taken into account the variation of $\mathrm{HR}$ and $\mathrm{ER}$ with solid concentration $(\mathrm{Cw})$ and mass median diameter $\left(\mathrm{d}_{s_{0}}\right)$. Kazim et al. [2] used an Ni-hard metal impeller of $270 \mathrm{~mm}$ diameter, while $\mathrm{Ni}$ et al. [10] used centrifugal impeller of $400 \mathrm{~mm}$ diameter, $100 \mathrm{~mm}$ wide at discharge, 3 logarithmic vans having 20degree inlet angle,17-degree outlet angle and 5 degree overlapping angle. The comparison was carried out at best efficiency point, and show the same linear relation and the difference of the results due to the difference of pump size, particle size and solid specific gravity.

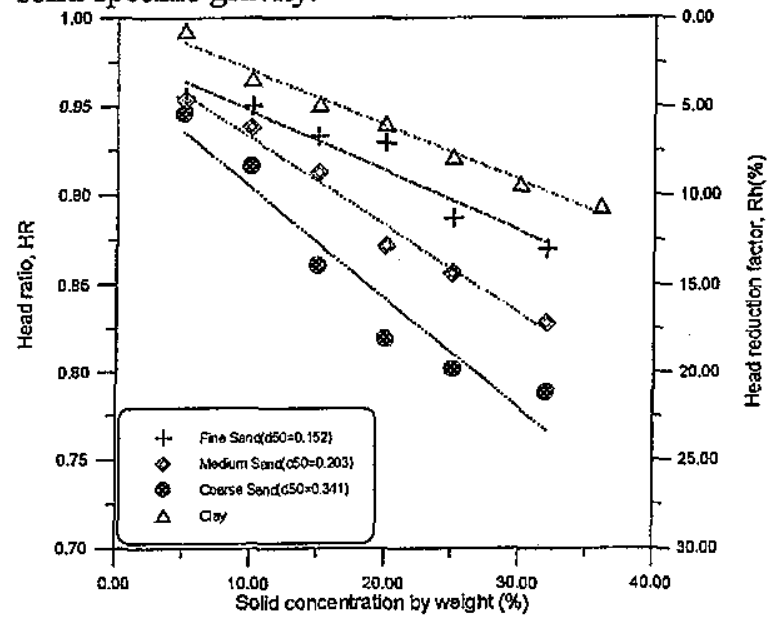

Fig.11 Variation of $H R$ and $R h$ with solid concentration for

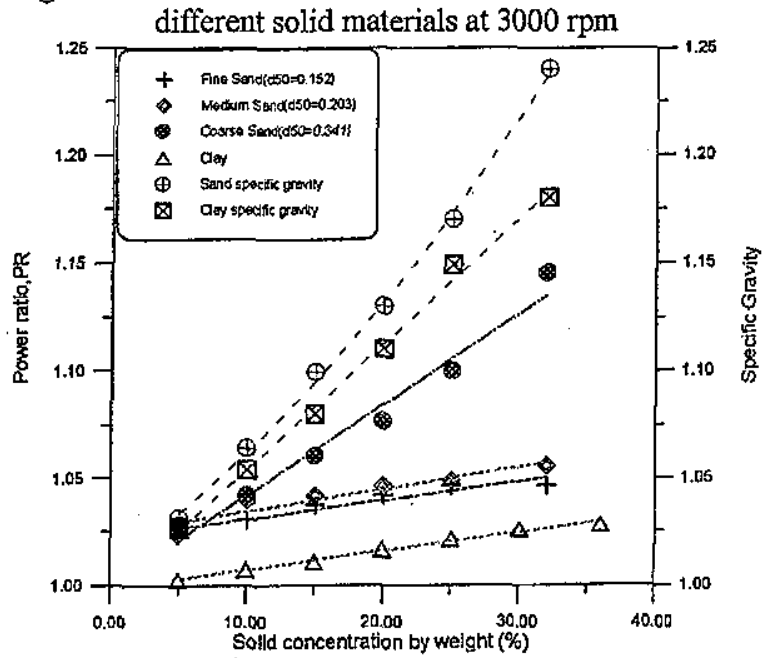

Fig.12 Variation of power ratio and specific gravity with solid concentration for different solid materials at $3000 \mathrm{rpm}$ 


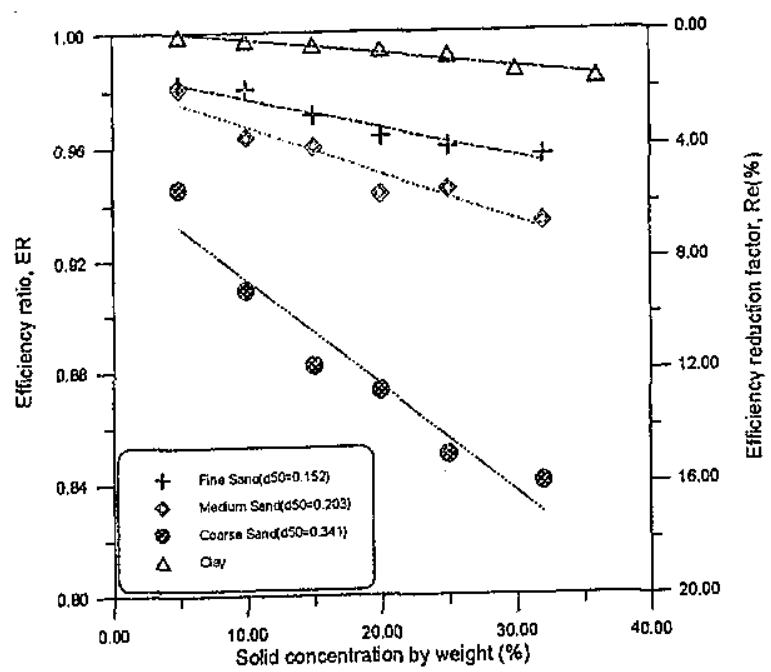

Fig.13 Variation of ER and Re with solid concentration for

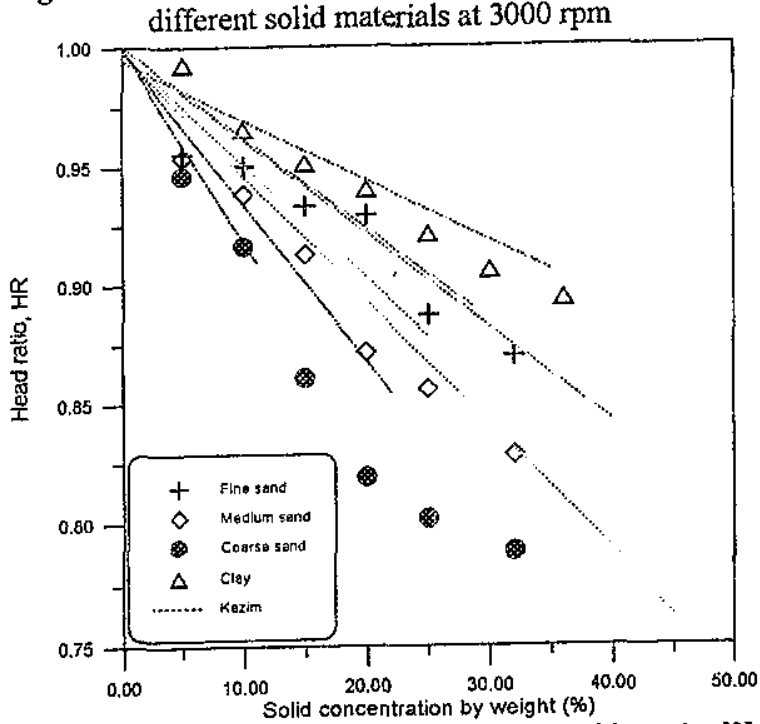

Fig.14 Comparison of the experimental results with Kazim [2]

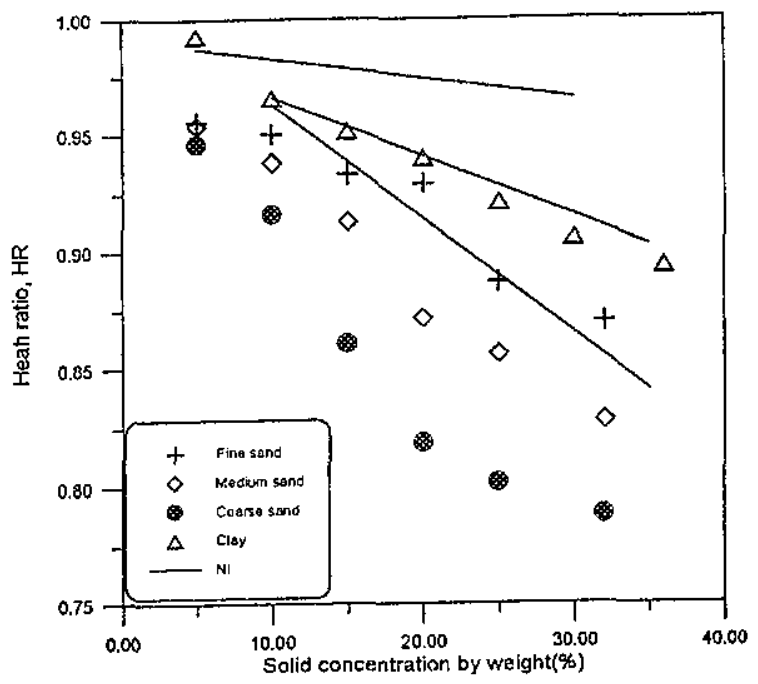

Fig.15 Comparison of the experimental results with $\mathrm{Ni}[10]$

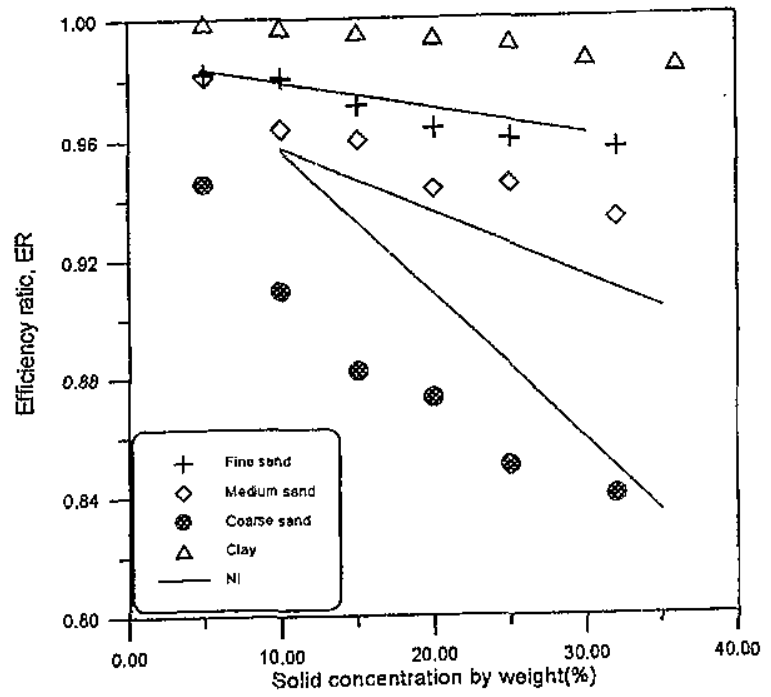

Fig.16 Comparison of the experimental results with $\mathrm{Ni}[10]$

\section{CONCLUSIONS}

From the present experimental investigations on the centrifugal pump characteristics with different slurries, the following broad conclusions can be obtained:

1. The head and efficiency of the pump decrease with increase in solid concentration, and the particle size.

2. Sand size has a strong influence on characteristic of the pump. The efficiency reduction factor for the clay and fine sand slurry is rather small, while the factors for the medium sand at $\mathrm{Cw}=32 \%$ and the coarse sand at $\mathrm{Cw}=32 \%$ reach $\mathrm{Re}=6.7 \%$ and $16 \%$, respectively.

3. For the high concentrations of the coarse sand power ratio $(P R>1)$ and therefore power requirement increases nonlinearly with the slurry relative density.

4. For the clay, fine sand, and medium sand slurry, $E R \approx H R$, and therefore $P R \approx 1$ holds for the concentration at least up to $10 \%$.

5. For the coarse sand slurry the pump head drops much faster than the pump efficiency when $\mathrm{Cw}=15 \%$.

\section{NOMENCLATURE}

$\mathrm{BEP}=$ best efficiency point

$\mathrm{B}=$ blade height $(\mathrm{mm})$

$\mathrm{Cw} \quad=$ solid concentration by weight (percent)

D = blade diameter $(\mathrm{mm})$

$\mathrm{d}_{50} \quad=$ mass average particle diameter $(\mathrm{mm})$

$\mathrm{d}_{\mathrm{w}} \quad=$ weighted mean diameter $(\mathrm{mm})$

HR = Hs/Hw (head ratio)

PR $=$ Ps/Pw (power ratio)

$\mathrm{ER}=\mathrm{Es} / \mathrm{Ew}$ (efficiency ratio)

$\mathrm{Rh}=1-\mathrm{HR}$ (head reduction factor) 


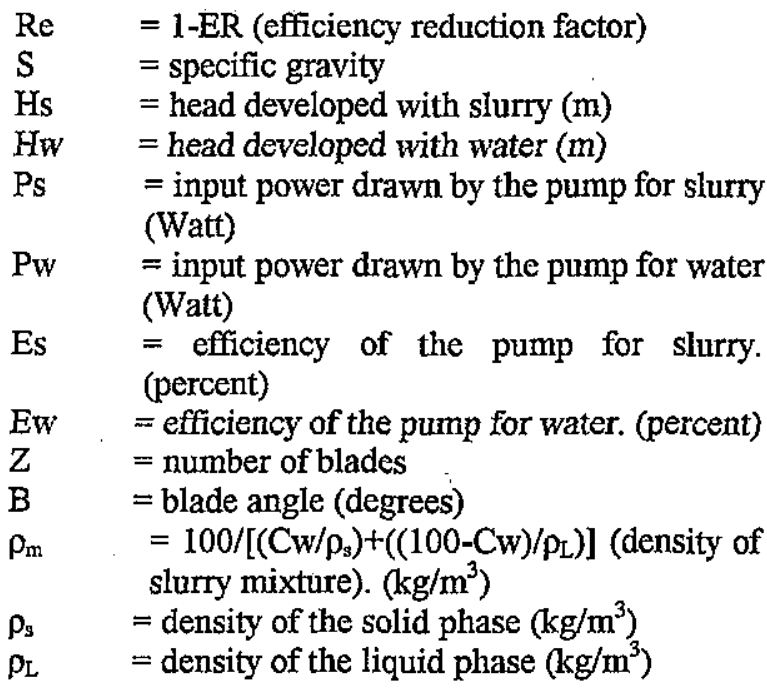

\section{REFERENCES}

[1] Mez, W., 1984,"The Influence of Solid Density and Grain Size Distribution on the Working Behavior of Centrifugal pumps"Proc. Hydrotransport-9, Paper H1,BHRA Fluid Engineering, pp. 345-358.

[2] Kazim, K. A., Maiti, B., and Chand, P., 1997,"A Correlation to Predict the Performance Characteristics of Centrifugal Pumps Handling Slurries "Proc. Inst. Mech. . Engrs, 21A, pp. 147157.

[3] Sellgren, A., and Vappling, L.,1986, "Effects of Highly Concentrated Slurries on the Performance of Centrifugal Pumps" Proc. International symposium on Slurry Flows, FED, ASME, USA, Vol.38, pp. 143-148.

[4] Wilson, G., 1989, "The Effects of Slurries on Centrifugal Pump Performance" Proc. of the 4th International Pump Symposium, Houston, Tx , pp. 19-25.

[5] Sellgren , A., and Vappling , L., 1989 "Effects of Highly Concentrated Slurries on the Performance of Centrifugal pumps," ASME Fluids Engineering Div., FED. Vol, 38 ASME, New York, pp. 143-148.

[6] Sellgren, A., and Addie, G., 1989,"Effect of Solids on Large Centrifugal pumps Head and
Efficiency," paper CEDA Dredging Day, Central Dredging Association, Amsterdam, The Netherlands.

[7] Gahlot, V. K., Seshardri, V., and Malhotra, R.C., 1992,"Effect of Density, Size Distribution, and Concentration of solids on the Characteristics of centrifugal pumps," ASME J. Fluids Eng., 114, pp.386-389.

[8] Sellgren , A. , and Addie ,G.R., 1993, " Solids Effect on The Characteristics of Centrifugal Slurry Pumps, "Hydro transport - 12, 12th .Int .Conf . on Slurry Handling and Pipe Line Transport, Belgium, sept . 28 -30, BHRA Fluid Engineering, pp .3-18.

[9] Kazim, K. A., Maiti, B., and Chand, P.,1997,"Effect of Particle Size Distribution, Specific Gravity and Solids Concentration on Centrifugal pump Performance," Powder Handle, Proces, $g(1), p p .27-32$.

[10] $\mathrm{Ni}, \mathrm{F}$., Vlasblom, W. J., and Zwartbol, A, 1999,"Effects of High Solid Concentration on Characteristics of a Slurry Pump," Hydrotansport-14, BHRA Group, pp. 141-149

[11] Sellgren, A., Addie, G .R., and Scott, S., 2000 ,"The Effect of Sand-Clay Slurries on the Performance of Centrifugal Pump," Can .J. Chem .Eng., 78,pp,765-769.

[12] Gandhi, B.K., Singh, S .N., and Seshadriv, V., 2000 ," Improvements in the Perdition of Slurry Pumps Handling Slurries, "Proc. Inst. Mech . Engrs . 214A, pp. 473-486.

[13] Gandhi. B.K., Singh, S. N., and Seshadri, V., 2001," Performance Characteristics of Centrifugal Shurry Pumps," ASME J, Fluids Eng. 123, pp.271-280.

[14] Gandhi, B. K., Singh, S.N., and Seshadri, V., 2002 ,"Effect of Speed on the performance Characteristics of Centrifugal Slurry pump," Journal of Hydraulic Engineering, pp.225-233.

[15] Engin, T., and Gur, M.,2003,"Comparative Evaluation of Some Existing Correlations to Predict Head Degradation of Centrifugal Slurry Pumps," ASME. J. Fluids Eng., 125, pp.149-157. 